\title{
Ultrasound-promoted iodination of aromatic compounds in the presence of iodine and hydrogen peroxide in water.
}

\author{
Irlon M. Ferreira, Rafael D. C. Gallo, Gleison A. Casagrande, \\ Lucas Pizzuti` and Cristiano Raminelli`
}

Faculdade de Ciências Exatas e Tecnologia, Universidade Federal da Grande Dourados, Dourados, MS, Brazil *e-mail addresses: lucaspizzuti@ufgd.edu.bror raminelli@ufgd.edu.br

Keywords: iodination reaction, ultrasound, sonochemical synthesis

\section{INTRODUCTION}

Recently we published the diiodination reaction of phenols using $\mathrm{I}_{2}$ and $\mathrm{H}_{2} \mathrm{O}_{2} 30 \%$ in water at $50{ }^{\circ} \mathrm{C}$ for $24 \mathrm{~h}^{1}{ }^{1}$ The use of ultrasound as a tool in organic synthesis, generally, decreases the reaction time and increases the yields of the desired products. Accordingly, we decided to employ ultrasound in the synthesis of iodinated aromatic compounds using $\mathrm{I}_{2}$ and $\mathrm{H}_{2} \mathrm{O}_{2} 30 \%$ in water at room temperature.

\section{RESULTS AND DISCUSSION}

Initially, a mixture of phenol (1a), 2 equiv. of $\mathrm{I}_{2}$ and 4 equiv. of $\mathrm{H}_{2} \mathrm{O}_{2} 30 \%$ in water was subjected to sonication by using a probe, operating at $20 \mathrm{KHz}$ of frequency and $100 \mathrm{~W}$ of potency. The reaction progress was monitored by TLC and the reaction temperature was measured with a thermometer every $15 \mathrm{~min}$. Under these reaction conditions 2,4,6triiodophenol (2a) was obtained in a $74 \%$ yield in only 60 min (Table 1, entry 1 ). Next, we repeated the same reaction presented in entry 1 in the absence of $\mathrm{H}_{2} \mathrm{O}_{2} 30 \%$ and we did not obtain 2,4,6-triiodophenol (2a) (entry 2). This result shows that the success of the transformation depends on the presence of $\mathrm{H}_{2} \mathrm{O}_{2}$ $30 \%$. Afterwards, aromatic and heteroaromatic compounds were subjected to the sonication in the presence of $\mathrm{I}_{2}$ and $\mathrm{H}_{2} \mathrm{O}_{2} 30 \%$ in water leading to the formation of iodinated aromatic and heteroaromatic compounds, as can be seen in Table 1 .

\section{CONCLUSION}

The iodination reaction of aromatic and heteroaromatic compounds with $\mathrm{I}_{2}$ and $\mathrm{H}_{2} \mathrm{O}_{2} 30 \%$ in water employing ultrasound resulted in the formation of iodinated aromatic and heteroaromatic compounds in isolated yields from 40 to $100 \%$ and in reaction times between 30 and 90 min.

\section{ACKNOWLEDGEMENTS}

We thank CNPq and FUNDECT for support.

\section{REFERENCES}

${ }^{1}$ Gallo, R. D. C.; Gebara, K. S.; Muzzi, R. M.; Raminelli, C. J. Braz. Chem. Soc. 2010, 21, 770-774.
Table 1. Synthesis of iodinated compounds (2) using $\mathrm{I}_{2}$ and $\mathrm{H}_{2} \mathrm{O}_{2} 30 \%$ in water under ultrasound irradiation.

(min)

